\title{
Planeamiento urbanístico, promoción inmobiliaria y Arqueología involuntaria
}

\author{
Ma. Magdalena Riera i Frau*
}

En las Islas Baleares la propiedad y explotación del suelo a nivel de especulación urbanística y/o turística constituye la principal fuente de acumulación de riqueza. En lo que atañe a las islas de Mallorca e lbiza la sobreexplotación de los recursos paisajísticos ha conducido a la actual situación en la que la mayoría del territorio, especialmente en las zonas costeras, se encuentra urbanizado y en muchos casos se ha destruido irremediablemente el recurso que se pretendía explotar, el paisaje.

Esta destrucción ha implicado también la desaparición de un porcentaje de elementos integrantes del patrimonio histórico imposible de evaluar. En este escrito se pretende analizar las distintas estrategias que se utilizan en la actualidad para continuar esa destrucción enmascarándola bajo preceptos legales, amparados en discursos conservacionistas que son su justificación más operativa.

En una narración de Italo Calvino figura la siguiente definición: ¿Qué será el género humano en el momento de la extinción? Cierta cantidad de información sobre sí mismo y sobre el mundo, una cantidad finita, dado que ya no podrá renovarse ni aumentarl. Esa información, cuando toma un carácter histórico o patrimonial, tiene esa cualidad de no renovable que hace que pueda ser analizada desde una óptica muy similar a la utilizada para los recursos naturales. Desde este punto de vista los elementos que integran el patrimonio histórico entendidos como contenedores de información histórica podrían considerarse un recurso limitado y no renovable.

Tal recurso ha sido utilizado o destruido en función de la obtención de un beneficio económico y, en el momento actual, la situación sólo ha variado en la utilización de discursos y marcos legales aparentemente más democráticos, para utilizar un concepto lo más general posible.

El desarrollo turístico que se produce en los años sesenta en la isla de Mallorca y la actividad urbanizadora que tal desarrollo comporta tuvo un doble efecto sobre el patrimonio histórico. Por una parte, supuso la destrucción de una cantidad de recursos difícil de calibrar y, por otra, la creación de un marco legal basado en la protección por decreto.

Un decreto de 1964 declaró Conjunto Histórico-Artístico el casco antiguo de la ciudad de Palma², ocultando bajo esa declaración la posibilidad de realizar reformas urbanísticas y proyectos arquitectónicos planificados desde $1943{ }^{3}$ que supusieron no sólo la destrucción de una parte importante de la ciudad medieval sino también la obtención de importantes beneficios económicos para el capital isleño ${ }^{4}$. La operación es justificada por el arquitecto G. Alomar Esteve, autor del plan de reforma de 1943, del Decreto de Protección de 1964 y creador de la empresa E.U.S.A. de la siguiente forma: "El momento era oportuno económica y socialmente: no había trabajo ni para los obreros ni para los empresarios; la gente iba camino de morirse de hambre; no había industria local por falta de materias primas; los comerciantes necesitaban vender y la gente no compraba porque no tenía dinero. Había además una gran falta de viviendas. El "estraperlo" estaba a la orden del día. Las reformas ayudarían sin duda a resolver esta situación"'s.

Aunque estas circunstancias habían desapareci- 
do en 1964 el decreto de protección del casco antiguo de Palma mantuvo parte de las reformas, dejando las zonas que ellas cubrían fuera de protección. Ante tal circunstancia seguía siendo más rentable invertir en las zonas de reforma que en el resto del centro histórico.

En 1966, siendo Comisario General del Patrimonio Artístico Nacional el mismo G. Alomar Esteve, se aprobó un decreto por el que se declaraban Monumento Histórico-Artístico todos los monumentos prehistóricos y protohistóricos de las islas de Mallorca y Menorca6. Las instrucciones para la defensa de tales monumentos concluían señalando que "los monumentos y restos contenidos en el Inventario, sea cual sea su estado de conservación son, en todo caso, indestructibles y el espacio contenido en el polígono envolvente es inedificable"7.

La efectividad del decreto y la voluntad de aplicarlo dependió siempre de intereses diversos, así en la actualidad han desaparecido el $17 \%$ de los monumentos inventariados entonces8. Ya en 197| fue destruido el conjunto prehistórico de Son Oms para construir la segunda pista del aeropuerto de Palma; la voladura pudo realizarse con todos los beneplácitos legales aunque ese conjunto gozaba incluso de una declaración específica ${ }^{9}$.

La trasferencia de las competencias en materia de cultura a la Comunidad Autónoma de las Islas Baleares (1983) junto con la aprobación de la ley 16/1985 del Patrimonio Histórico Español supusieron el cambio del marco en que hasta ese momento se habían desarrollado las investigaciones. El acercamiento de la administración al territorio objeto de estudio supuso cambios sustanciales que finalmente han llevado a subordinar todavía más la labor arqueológica a la evolución política y económica de las islas. La superación de la política de protección por Decreto ha sido sucedida por una asunción de la tarea de protección del patrimonio y la integración de ésta en el conjunto de los intereses urbanísticos.

Se ha dedicado a las tareas de inventario de yacimientos arqueológicos, a través del denominado Programa de Preservació de Jaciments Arqueològics 10 , la práctica totalidad del presupuesto de arqueología de la Conselleria de Cultura del Gobierno autónomo. Esta catalogación ha tenido como consecuencia la delimitación de unas reservas culturales y de paisaje.
La inexistencia de normativa con respecto a los yacimientos catalogados hace en estos momentos imposible establecer cuál es la suerte que puedan correr en un futuro inmediato.

Esta operación, por otra parte, no es en absoluto inocente ya que ha favorecido los intereses de los promotores turísticos con la especulación del suelo ya desarrollada frente a aquellos que, poseyendo el remanente de suelo sin explotar, pretenden ahora proceder a la urbanización. La disputa entre estos dos grupos marca la vida políica de las Baleares desde la creación de la Comunidad Autónoma provocando situaciones confusas en las que los actuales conservacionistas del patrimonio natural y cultural son los herederos de los primeros destructores.

Mientras se iban realizando dichas tareas de inventario la renovación arquitectónica de los centros históricos ha provocado la remoción del subsuelo y con ella ha surgido la necesidad de realizar multitud de controles y excavaciones arqueológicas.

Si se compara la situación actual con la de los años 6011 se observan diferencias fundamentales. Los Ayuntamientos han aprobado instrumentos de planeamiento que facilitan la realización de excavaciones; los promotores de obras, sean públicos o privados, financian las tareas de excavación y los arqueólogos comunmente denominados de urgencia han conseguido un status profesional que les equipara a otros grupos de profesionales liberales.

Independientemente de los casos de flagrante connivencia entre los promotores inmobiliarios y los arqueólogos que puedan ir planteándose, la situación expuesta merece ser analizada en cada uno de sus puntos.

El planeamiento urbanístico desarrollado por los Ayuntamientos democráticos, de los cuales es un buen ejemplo el P.G.O.U. de Palma (1985), introdujeron nuevos conceptos y normas que parecían tendentes a conseguir una mayor protección del patrimonio histórico y especialmente de aquel concentrado en los núcleos urbanos.

Frente al planeamiento anterior que facilitaba la destrucción de yacimientos y edificios se creó un cuerpo normativo que ha permitido el control 
arqueológico de las obras y que sentaba unas estrictas bases para la intervención en el patrimonio arquitectónico.

Entendemos que este tipo de planeamiento, si bien ha evitado multitud de enfretamientos puntuales, parte de un error de base que lo convierte en enormemente destructivo. Las facilidades para la realización de excavaciones arqueológicas no implican el cumplimiento del deber de conservación sino el pasar por un trámite, la excavación, que permite hacer desaparecer, ya para siempre, el problema. Volviendo al discurso inicial sobre los recursos limitados y no renovables, el planeamiento urbanístico no debería potenciar la excavación, el consumo rápido y a veces irracional de ese recurso, sino potenciar la utilización de los recursos técnicos que permiten frenar la manipulación del subsuelo.

El planeamiento urbanístico, con toda la rigidez normativa que quiera dársele, no ha hecho, hasta el momento, más que señalizar, a veces de la forma más luminosa posible, las vías a seguir para intervenir, en el sentido de operar, sobre el patrimonio histórico y, en cambio, no ha dado paso ni a la actuación científica, la excavación planificada imprescindible para la obtención de un determinado conocimiento histórico, ni a la creación arquitectónica, tanto la derivada de la lectura particular de cada edificio como aquella que, aunque destructiva, contribuya a incrementar la carga patrimonial de los centros históricos.

El promotor inmobiliario ha descubierto muy recientemente los beneficios que aporta la manipulación del patrimonio histórico. De hecho, parece que los primeros interesados han sido aquellas personas que conjugan su condición de promotor, sea público o privado, con la de técnico en rehabilitación. El descubrimiento de restos arqueológicos o estructuras arquitectónicas fosilizadas en la edificación ha permitido, con su supuesta revalorización, encubrir una mala arquitectura, ha facilitado la obtención de "prioridad en las subvenciones"I2 y ha incrementado el beneficio al introducir el concepto de prestigio en la valorización del edificio.

Todo este entramado de intereses tiene como fruto la denominada arqueología involuntaria, aquella en la que el arqueólogo no excava lo que quiere ni cuando quiere, sino que se limita a facilitar el tránsito por los caminos del planeamiento urbanístico. En este punto el arqueólogo se convierte estrictamente en un técnico, en el más estricto sentido de la palabra, que juega con intereses económicos.

Ante esta situación sólo cabe confiar en la honradez particular de los técnicos que manipulan el patrimonio histórico e intentar frenar el uso irracional y en pro del beneficio particular de unos recursos limitados y no renovables.

\section{NOTAS}

I CALVINO, I.: La memoria del mundo, in La Gran Bonanza de las Antillas, Barcelona, 1993, p. 162

2 Decreto de II de Junio de 1964 (B.O.E. 2 de Julio).

3 Ordenanzas Municipales de la Edificación, Ayuntamiento de Palma, 1944.

4 Véase la creación de la empresa E.U.S.A. con participación de capital de la familia March y que fue la adjudicataria de las reformas: "Estos pequeños hechos que acabo de referir, como es de suponer, no se publicaron en la prensa, aunque el hecho de que March financiara la discutida Reforma -con gran escándalo por parte de un sector que todavía pensaba ser dominante pero que ya no lo era, empezando por algunos aristócratas y por los deudos de don Manuel Salas, el otro gran capitalista de las islas- no tardó en ser de dominio público. El abogado don Luis Alemany y el director de la Banca March don Emilio Tramullas, pasaron a ser, juntamente con nosotros, consejeros de la sociedad adjudicataria E.U.S.A.". ALOMAR ESTEVE, G.: Memorias de un urbanista 1.9391979, Palma, 1.986, p.45.

\section{Idem p. 42}

6 Decreto 2563/1966 de 10 de septiembre, por el que se declaran Monumentos Histórico-Artísticos todos los monumentos megalíticos, cuevas prehistóricas y otros restos prehistóricos y protohistóricos de las islas de Mallorca y Menorca.

7 Instrucciones para la defensa de los sitios arqueológicos y científicos I: Monumentos prehistóricos y protohistóricos de la isla de Mallorca. Ministerio de Educación y Ciencia. Palma, 1967. 
8 PONS, G., RIERA, M.M., TORRES, F.: Inventari arqueològic de Mallorca: els monuments a l'àmbit rural. Bolletí de la Societat Arqueològica Lul.liana 46, Palma, 1990, p. 277.

9 Decreto 1070/I.963 B.O.E. 20 de mayo idem. Monumento histórico-artístico. El conjunto talayótico de Son Oms, en el término municipal de Palma de Mallorca, provincia de Baleares.

10 PONS, G., RIERA, M.M., TORRES, F.: Op.cit.
II ROSELLO BORDOY, G.: Excavaciones arqueológicas en Palma de Mallorca. Sondeos en el casco antiguo, in Mayurqa 2I, Palma, 1987.

12 ALEMANY, Luis: Proyecto de rehabilitación de las calles Pau, Zagranada y Bordoy in Jomadas de rehabilitación: La intervención en el centro histórico, Palma, 1992, p. 116. 

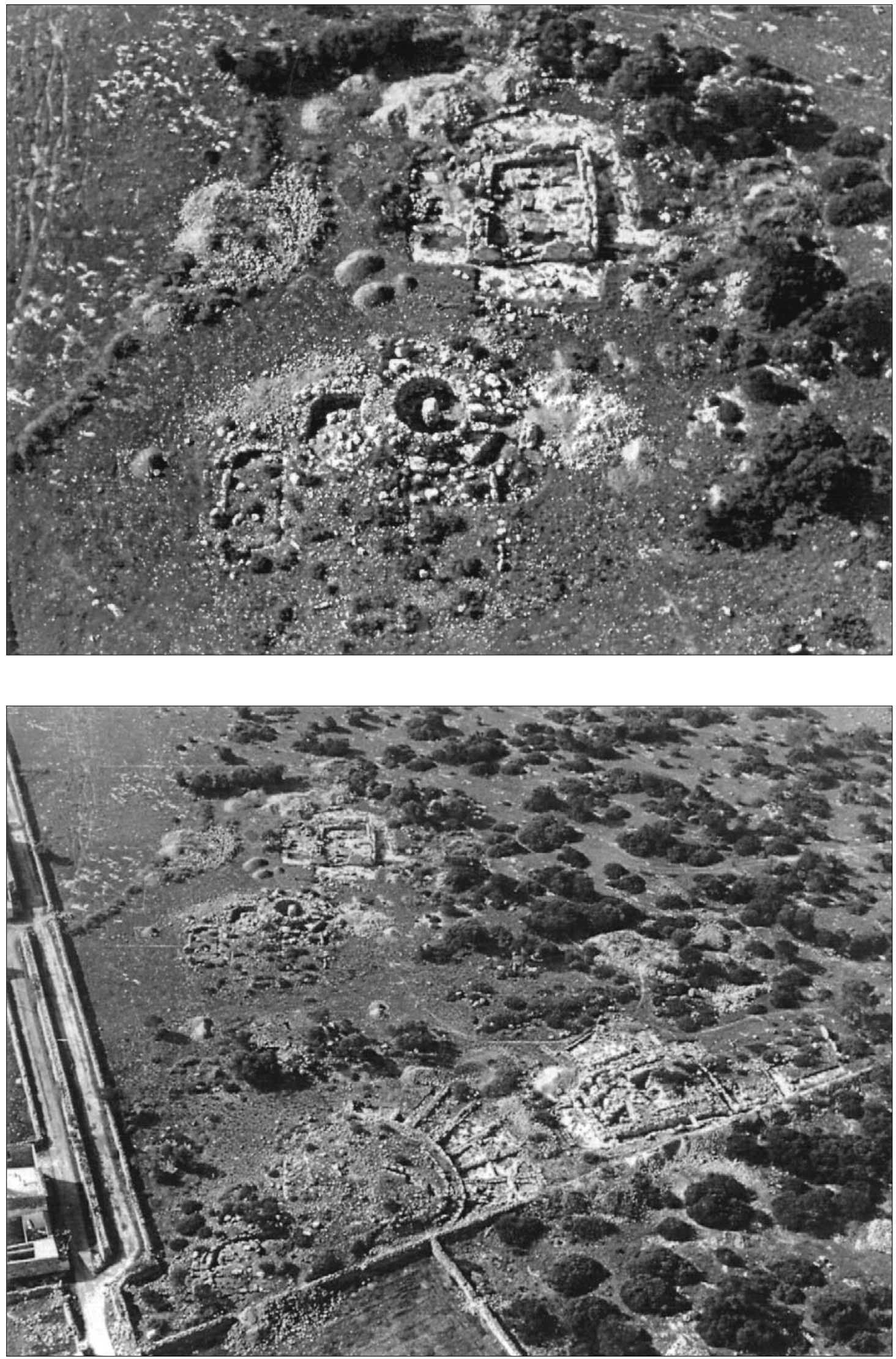

Fig. I. El conjunto prehistórico de Son Oms antes de su destrucción (1970) 

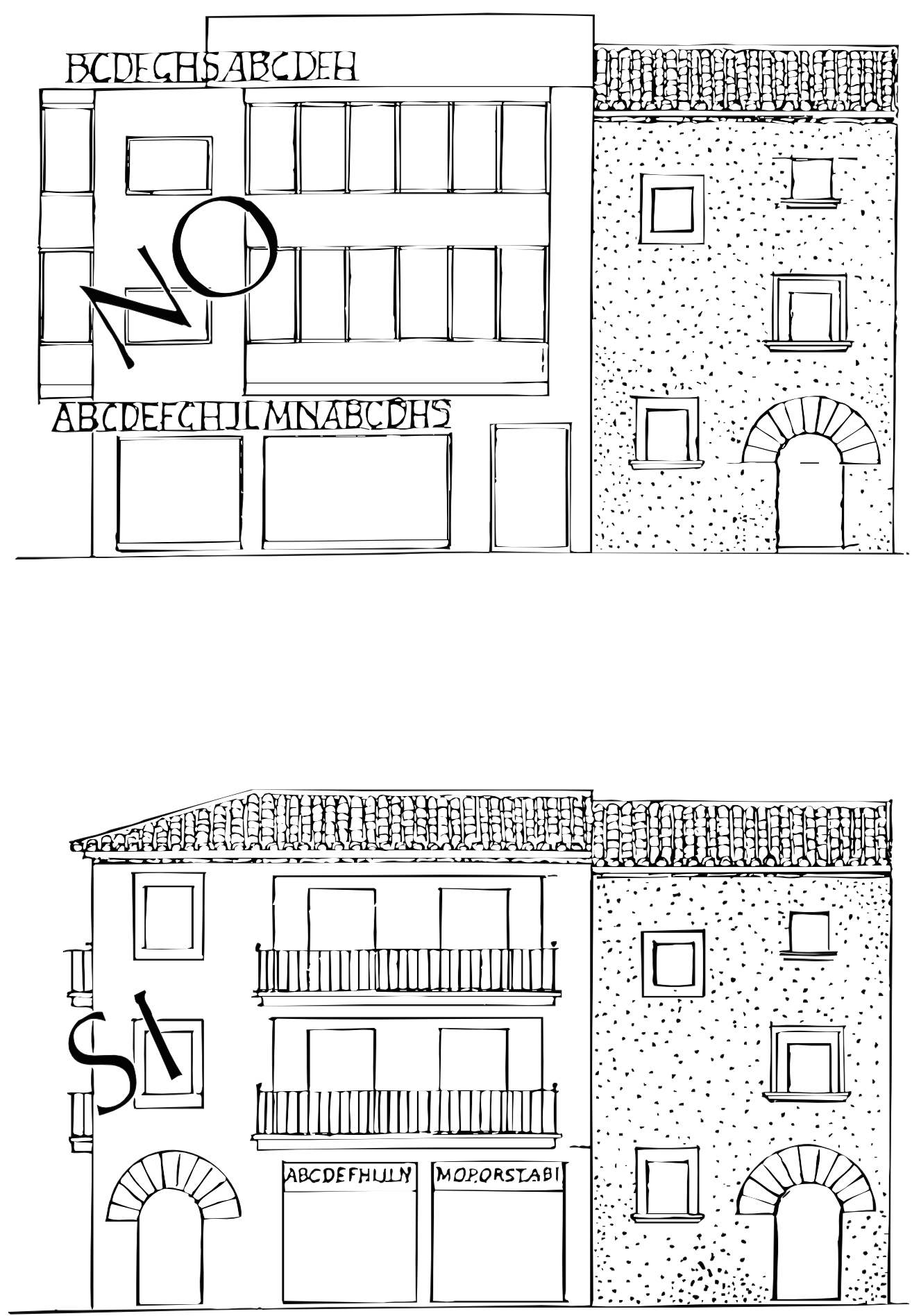

Fig. 2. Directrices para la nueva edificación según los criterios rectores e instrucciones para la defensa de los conjuntos y monumentos histórico-artísticos de la Isla de Mallorca. Obsérvese que estructuralmente se trata del mismo edificio 


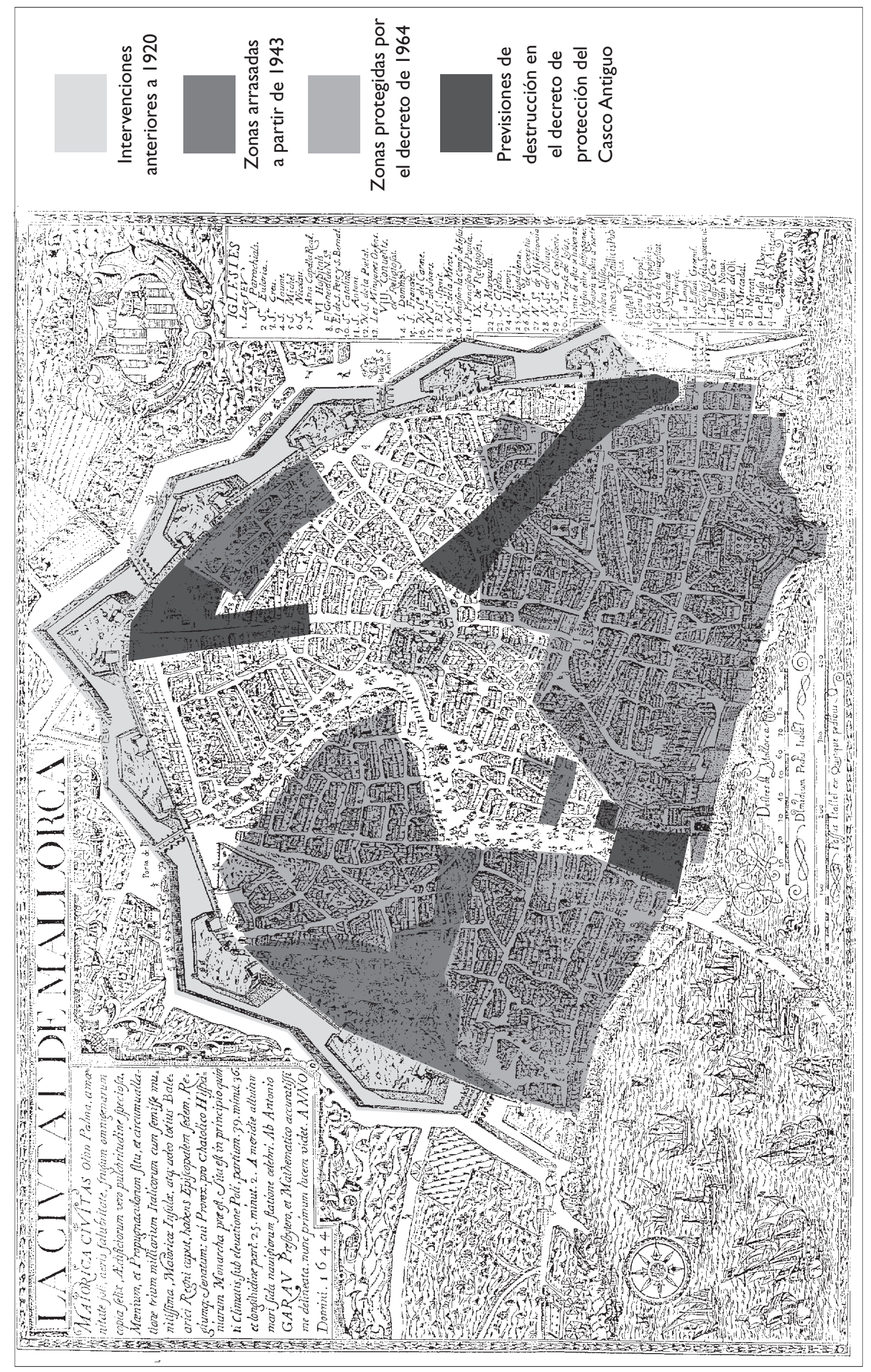

